\title{
Factors Influencing Team Performance in Software Development Projects
}

\author{
S. M. Samarasinghe ${ }^{a^{*}}$, S. S. U. Samarasinghe ${ }^{b}$ \\ ${ }^{a}$ University of Sri Jayewardenepura, Nugegoda, 10250, Sri Lanka \\ ${ }^{b}$ Ebeyonds Ltd, Pannipitiya, 10230, Sri Lanka \\ ${ }^{a}$ Email: malkanthi@sjp.ac.lk \\ ${ }^{b}$ Email: udanjala@gmail.com
}

\begin{abstract}
The performance of software development teams is an important topic in the field of IT projects. Previous research has found that the factors such as communication, cohesion, mutual support, coordination of expertise, trust and value diversity affect performance of team members in software development projects. However, the findings of existing studies cannot be directly applied to the Sri Lankan context due to cultural and behavioural differences of people in Sri Lanka compared to western countries. Thus, the aim of this study was to investigate the factors influencing the team performance in software development projects in Sri Lankan IT companies, as Sri Lanka is one of the emerging countries engaged in software development projects. Thus, the study examined the factors influencing effective and efficient team performance in software development projects. This study mainly considered a sample of 186 IT professionals who work in large-scale IT companies in Sri Lanka, and the data was collected through an online questionnaire. Based on the results, the hypotheses were tested to identify the effect of each influencing factor on the performance of software project teams. It was found that communication, cohesion, trust, value diversity and coordination of expertise have significant positive effect on team performance. The findings of this study would be useful for managers, team leads and project managers to enhance the performance of software development teams.
\end{abstract}

Keywords: Team performance; Team quality; Software development projects; IT professionals.

* Corresponding author. 


\section{Introduction}

Information Technology (IT) industry drives productivity and innovation in almost every economic sector, helping businesses of all sizes perform better. Today, IT industry is one of the fastest growing industries. It helps both developed and developing countries to design and develop new products and access new markets as well as partners and investors. It is a field with vast potential as the applications of IT in the service of business are limitless [1]. Sri Lanka is an emerging global IT destination, where the IT industry is one of the fastest growing IT markets in the region. In 2007, Sri Lanka was ranked among the Top 50 Global Outsourcing destinations by AT Kearney [1,2] and in the last three consecutive years, Sri Lanka was able be ranked among top 25 in the index [3]. Moreover, Sri Lanka was ranked $21^{\text {st }}$ in the Global Services Location Index in the year 2011 [2]. Considering the above statistics, it is evident that the IT industry in Sri Lanka plays a major role in the country's economy. Over 60,000 people are being employed in the IT industry in Colombo and the annual growth rate of the workforce is over $20 \%$ [4]. The private sector is largely engaged in IT software development projects in Sri Lanka, and many foreign investors have started their development centers within the country due to the skilled workforce and the quality of projects and deliverables. In the recent years, the IT industry in Sri Lanka has suffered problems related to the project completion rate [1,5]. This is not only a local issue, at global level too, many IT firms face the issue of completing the projects successfully. According to [6], 32\% of IT projects had low success rate, while $44 \%$ surpassed the planned budget and time. $24 \%$ of the projects failed [7]. Furthermore, according to a recent study done by PricewaterhouseCoopers by reviewing 10,640 projects from 200 companies in 30 countries, it is reported that only $2.5 \%$ of the companies successfully completed $100 \%$ of their projects. Hence, completing software development projects successfully have become a challenging task for companies, and software development can be considered as a high-risk enterprise $[8,9,10]$. Many companies implement rigid processes that dictate behaviour and use statistical methods to control the quality of the project by implementing techniques such as Six Sigma, Kaizen etc. Process guides support work practices, while quality control systems assess and improve outcome [11]. Besides these approaches, the rate of project failure does not seem to be decreasing. That is mainly because current project management tools, techniques, and theories account for the rational components of project management, but they overlook the emotional components that account for a large part of a project's success [12]. Every software project will inevitably face the issue of team composition [8] that will lead to poor team performance. Hence, this research is mainly focusing on analyzing how to enhance software development team performance as the project team's behaviour is one of the key factors that drive successful project management. Based on previous work, two widely used approaches to measure team performance would be: (1) measuring individual performance and (2) measuring team level performance $[7,8]$. This study mainly focused on measuring team level performance only to measure project team performance. Hence, the purpose of this study is to examine the factors that influence or determine the team performance within a project team in IT projects in the Software Development industry in Sri Lanka.

\section{Literature review}

A project can be viewed as an "input-output model" [8, 13], where the input is transformed into output, under a set of constraints such as time, cost and quality. Many studies have been conducted in this context to identify what factors are affecting the completion of a project successfully. Many studies have identified team 
performance as a project success dimension [12,14,15,16]. Software development is primarily a team effort [7], and 'Teamwork' has been considered as a crucial factor in software development projects $[7,17,18,19]$. In project management principles, a common mistake that most of the organizations make would be putting their practices before people. Forcing team members to adopt project management practices and procedures may most likely to cause for the project to end up as a failure. According to literature, many researchers have cited that the key to project success is the people, basically the project team and the organization $[7,13]$. Hence, identifying the role of project team members is vital to complete a project successfully. A team is a small group, whose members have common purpose, complementary skills and interdependent roles [20]. Teams are social entities composed of members with high task interdependency and shared and valued common goals [21]. Reference [22] defined a team as a social system that consists of three or more people, where the members perceive themselves as 'members' and collaborate on a common task (teamwork) in an organization. A team can also be defined as a small number of people with complementary skills, who share a common purpose and goals, commitment with a common vision towards progress and are mutually responsible [23]. Hence, considering the above definitions, a 'Team' is defined as a social system with two or more people in an organization, who work collectively to achieve a common purpose and goals to complete a project to be delivered within a pre-specified time. The extent to which a team can meet established quality, cost and time and the set objectives, it is defined as team performance [18,22]. Team performance in software development can be analyzed as several dimensions, and among them, two common dimensions would be production performance and process performance [8]. According to [24], the concept of Input-Process-Output can be used to explore the key factors for group effectiveness. Production efficiency, member skills improvement and job satisfaction were used in this approach to measure team performance $[8,25]$. In literature many researchers have used [26] team performance measures: efficiency and effectiveness as the measurement variables that determine the productivity or performance of team members $[7,8,22,27]$. However, there are some counter arguments that it is inadequate to use only productivity (i.e. efficiency and effectiveness) to represent performance $[8,28]$. Some of the other variables that were used to measure team performance were, cost-schedule control [29,30], and the project-process [31,32]. However, for this study, the researcher will be using [26] team performance measures: efficiency and effectiveness as the measurement variables to determine the performance of team members. Effectiveness is defined as the degree to which a team meets the expectations of the quality of the outcome [7]. Generally, effectiveness is the quality of work produced [8]. In the case of software development projects, an effective performance is determined by to what extent the goals and the quality of the project were met [7]. Efficiency is defined as the extent to which the team met the estimated time and budget objectives and project constraints [7,22]. Team efficiency is evaluated in terms of adherence to project schedules [22]. It is the ratio of output to input [8]. Efficiency is a subjective measure [8] of team operations and project team staying within the target costs and schedule is important to complete a project successfully. In search of the factors that influence successful team performance, previous studies have examined quality factors within the team (teamwork quality) and various other personality characteristics of the team members as significantly related to team performance $[7,8]$. Factors such as communication, coordination, cohesion, balance of member contribution, mutual support, effort, trust, value diversity, knowledge diversity, social diversity (value diversity, knowledge diversity, and social diversity can also be known as 'team diversity'), management support, and heterogeneity were used by various researchers to assess how they influenced team performance 
$[7,8,22,33,34,35]$. The perception of project success can vary across the team members, the team leaders and different stakeholders of that project. For example, if one perceives a project to be a success or a failure, it does not imply that another has the same interpretation of success [7].

\subsection{Critical success factors related to team performance}

A comprehensive review of literature helped identify the critical success factors to formulate the research model. The critical success factors identified were communication, coordination of expertise, group cohesion, mutual support, value diversity and trust. These factors are discussed below.

\subsubsection{Communication}

Communication is the most primary component in teamwork that help exchange of information among team members, co-ordinate the efforts and provide feedback [22,36]. In an effective communication platform, the right information should be shared with the right person without distorting the original message [7]. If the message gets distorted while communicating, it might create failures as wrong information has been communicated. Hence, a feedback mechanism is useful, so that the sender and the receiver are both aware of the accuracy of communication. When the quality of communication is high within a team, it provides a basis for other factors that determine team performance [7]. Thus, communication can be considered as a pivotal factor that is essential to develop a high performing team. Hence, this study considered communication as a determinant of high team performance.

\subsubsection{Coordination of Expertise}

According to [37], co-ordination of expertise refers to the proper management of knowledge and skill dependencies within a team, which emphasizes on knowing where the expertise is located, recognizing the need for expertise and use of expertise to operations [7]. Software development teams are difficult to coordinate efficiently and effectively [37]. It is important that the team member contribute their task-relevant knowledge and experience to the team [22,25]. Reference [22] defined coordination as the extent to which individual efforts are well structured and synchronized within the team, while the balance of member contributions considers the degree to which team members can bring their expertise to their full potential. Considering various definitions, co-ordination of expertise is defined as the degree to which knowledge, experiences and skill dependencies among individual team members are managed effectively and synchronized within the team enabling them to pool their expertise to the highest possible level. Hence, this study considered co-ordination of expertise as an important factor for software development teams to increase team performance.

\subsubsection{Group Cohesion}

Cohesiveness is one of the most fundamental aspects of groups [38], thus identified as a critical success factor for team effectiveness [33], also [7,39] identified group cohesiveness as an important factor for team performance. Further, [33] identified members in a cohesive team support one another in the team to resolve conflicts among them avoiding hard feelings and they demonstrate the essence of togetherness. Lack of 
cohesion among team members will leads to political problems within the team. When the level of cohesion increases, the level of conformity to group norms will also get increased [33,40]. Therefore, cohesion can be considered as a predecessor of [7]. Although scholars have different viewpoints on cohesion and its effects on team performance, there are plenty of studies that show cohesion within the team is an important factor that creates a feeling of togetherness and results in high quality collaborations within the team. Hence, this study considers cohesion as an important factor for software development teams to increase team performance.

\subsubsection{Mutual Support}

Mutual support is an important competency that allows teams to be more effective by supporting one another to anticipate the needs of other team members [41]. Mutual support is the core aspect of teamwork. Mutual support is a core team skill and a crucial component in any teamwork process. Team members are required to be aware and understand the responsibilities as well as workload of fellow team members, so that other members of the team can help and backup team member(s) who cannot perform a task or who cannot meet a project deadline. According to [22], an individual's willingness to collaborate with others depends upon a co-operative state of mind. If the team members possess competitive behaviour, it would result in mistrust which leads to frustrated teams [22,42]. Previous studies done by [7,22,42] have showed that mutual support is an important factor that affects team performance. Hence, this study also considered mutual support as a variable that would affect team performances in software development projects.

\subsubsection{Value Diversity}

According to prior studies, team diversity exists in informational diversity, social diversity (also known as social category diversity) and value diversity. Since this study concentrate on team collaboration, this study will focus only on value diversity. Values direct the behavioural choices [8]. Value diversity occurs when team members perceive different values with respect to the team's tasks, project goals or mission $[7,8]$. Software development is a complex set of activities which calls for team members to be interdependent, and it is vital to have strong interactions among team members [7] to complete the project successfully. Value similarity within the team can reduce relationship conflicts by improving the extent to which group members identify each other [43]. Maintain a high morale within the team and to be efficient and effective within the team, low value diversity is vital [43]. Therefore, this study used value diversity as a critical factor for team performance in software development projects.

\subsubsection{Trust}

Trust defined as the extent to which a person believes that his/her team members are trustworthy or dependable [44]. Trust was identified as a critical factor for team performance in prior studies. Considering this view of trust, it is appropriate for teams engaged in software development projects, because the value of one member's contribution depends in part on the effort and contributions of others. According to the literature, the low levels of trust may be associated with lack of interest in project participation and decrease in contribution among team members [45]. Thus, trust is essential for knowledge sharing. Therefore, it is evident that trust is an essential 
prerequisite for effective functioning members within the team as well as an important success factor related to team performance in project management.

\section{Research Model}

In this study, the effect of critical success factors identified through literature related to team performance is analyzed with respect to team performance in Sri Lankan software development industry to identify which factors positively influence team performance. The research model for this study was developed based on the concepts of [22], and the findings of [7], and the other critical factors identified in the review of literature as factors that affect project team performance.

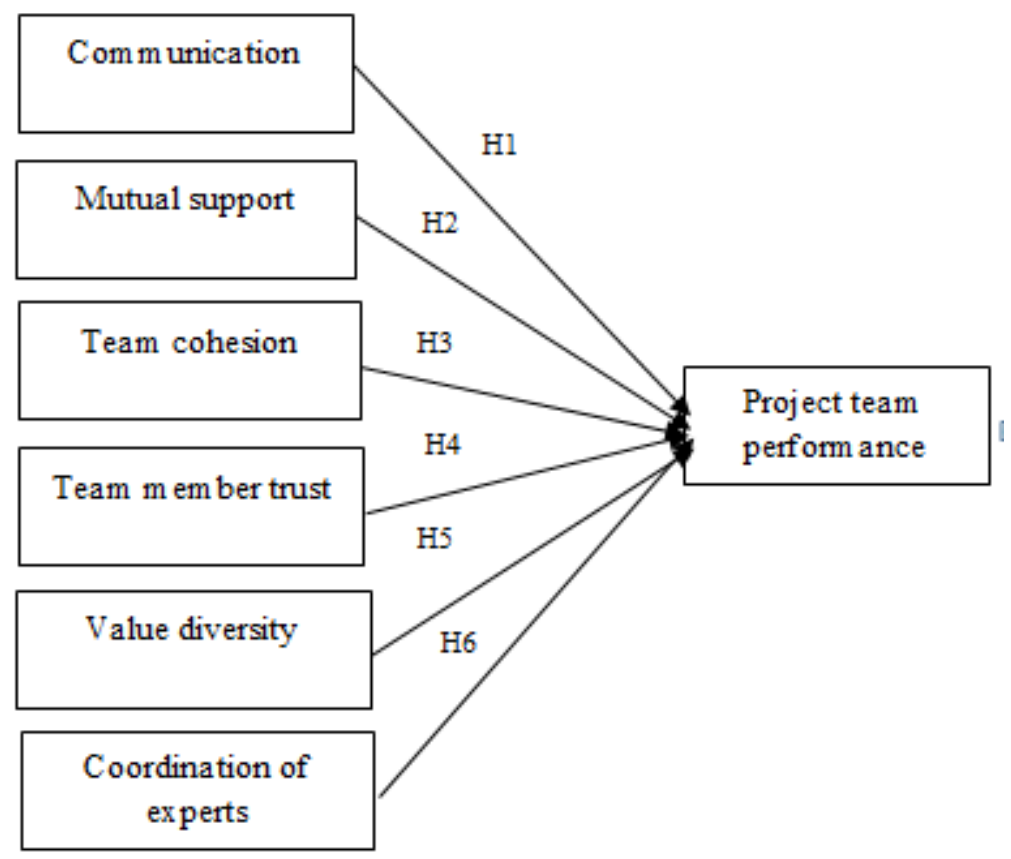

Figure 1: Research Model

\section{Hypotheses of the study}

Based on the literature it was evident that the communication plays an important role and is an influencing factor for team performance and project success. Communication is the primary component in teamwork to exchange information among team members, co-ordinate the efforts and to provide feedback [22,36]. Further, effective communication within software development team helps to ensure that members of a team shares the same mental model continuously [46] and facilitates trust within a team [7,45]. Therefore, based on the above justification, following hypothesis was formulated:

Hypothesis 1: Frequent communication among team members has a positive effect on software development team performance.

Previous studies identified mutual support as a significant factor that affects team performance [7,22,42]. 
According to [7], co-operation between team members gets increased when the quality and acceptance of ideas are high within the team. Therefore, mutual support can be considered as an important element of teamwork that enables the team members to reach the team goals in an efficient and effective way. Hence, based on the above justification, following hypotheses is formulate:

Hypothesis 2: Mutual support among team members has a positive effect on software development team performance.

In literature, team cohesion was identified as a factor influencing the performance of team members. It is one of the most fundamental aspects of groups and identified as a critical success factor for team effectiveness by prior studies $[33,38]$. Therefore, this study also will consider 'Team cohesion' as an influencing factor, and the to test whether the team cohesion among members has a significant influence on performance with regard to software development projects. Based on the above justification, following hypothesis was formulated:

Hypothesis 3: Team cohesion has a positive effect on software development team performance.

Many prior studies have identified trust as a significant predictor of team performance [44,47]. However, with regard to software development projects and team performance, it was identified as an influencing factor only in the [7] study that was conducted using data collected from 18 Dutch companies. Therefore, this study will test whether, trust among team members has a positive effect on increasing team performance and validate trust as an influencing factor for higher performance in software development projects. Based on the above justification, following hypothesis was formulated:

Hypothesis 4: Trust has a positive effect on software development team performance.

A group or a team is composed of people and when they are diversified will think and work in new ways and looks for innovative solutions. According to [7], value diversity of team members has been identified as an influencing factor that increases team performance in software development projects. Therefore, this study will also consider value diversity as a critical factor that affecs team performance in software development projects. In this hypothesis, the researcher will test whether that the diversity of values existing among the team members positively contributes to higher team performance in software development projects.

Hypothesis 5: Value diversity has a positive effect on software development team performance.

Co-ordination of expertise drives a knowledge sharing culture within the team, which is increasingly important when the complexity of software development team grows [48,49]. IS literature on cross cultural teams highlighted that cultural differences among team members can negatively affect team performance [49]. Hence, if the team is lacking in acknowledge/expertise sharing culture, it can negatively affect their performance. Moreover, References $[7,22,37]$ have proved that co-ordination of expertise existing among team members influences team performance by increasing efficiency and effectiveness of individual performance. Therefore, this study hypothesised that co-ordination of expertise has a strong positive relationship with team performance in software development projects. 
Hypothesis 6: Co-ordination of expertise has a positive effect on software development team performance.

\section{Population and sample}

The total population of this research consisted of all IT professionals who worked on at least one or more projects in Sri Lankan IT firms. This study focused on 10 large-scale organizations selected through convenience sampling method. The selected companies were having following characteristics: All companies are large-scale companies that employ more than 100 people, all companies are owned or funded by foreign companies or multinational corporations, all companies are offshore branches for parent companies located in United Kingdom, Sweden, America, and Singapore. Sampling frame comprised of 200 IT professionals; software engineers, project managers, team leads, consultants, business analysts and quality assurance analysts, who have worked on at least one or more software development projects at the chosen firms. Considering the average team size of 05 people, forty (40) software development teams were involved in this study.

\section{Data collection}

This study was a quantitative research study with the aim of achieving the proposed research objectives to find the answer for the research questions. Thus, this study used the questionnaire survey method for collecting data from the selected sample. Questionnaire consisted of already validated items from prior research. An online questionnaire was used to collect data as it was flexible and time-efficient with less risk of reliability errors and the collected data is easy to analyze using statistical tools [7]. A five-point Likert scale (anchored from strongly disagree to strongly agree) was used to measure responses for each construct considered for this study. A pilot survey was conducted to check the reliability of the online survey tool and adequacy of the questions. After the pilot survey, minor changes were made before distributing the questionnaire among the respondents. The online questionnaire was distributed among 200 participants covering 40 software development teams in 10 large-scale software development companies in Sri Lanka. In total, 186 questionnaires were usable in the data analysis. Initially data screening was carried out to ensure the accuracy of data before the main data analysis.

\section{Results}

Factor analysis was performed to check the convergent validity and discriminant validity. Principle component method was used as the extraction method and Promax method used as the rotation method for this factor analysis. According to Table 1, factor loadings were above the threshold 0.5 [50] and the items are well organized in the diagonal of the table. These diagonal loadings are high enough to conclude that these items have good correlation inside their own construct. This satisfied the convergent validity. Further, cross loadings were fairly small $(<0.5)$. Items measuring a particular construct did not correlate with other constructs. Therefore, it proved the discriminant validity. 
Table 1: Factor analysis

\begin{tabular}{|c|c|c|c|c|c|c|c|c|}
\hline \multirow{2}{*}{ Construct } & \multirow{2}{*}{ Item } & \multicolumn{7}{|c|}{ Factor Components } \\
\hline & & 1 & 2 & 3 & 4 & 5 & 6 & 7 \\
\hline \multirow{6}{*}{ Cohesion } & Coh2 & .870 & & & & & & \\
\hline & Coh1 & .798 & & & & & .376 & \\
\hline & Coh4 & .722 & & .392 & & & & \\
\hline & Coh6 & .692 & & & & & & \\
\hline & Coh5 & .643 & & & & & & \\
\hline & Coh3 & .517 & & & & & & \\
\hline \multirow{5}{*}{ Coordination of Expertise } & COE4 & & .944 & .386 & & & & \\
\hline & COE5 & .387 & .749 & & & & & \\
\hline & COE6 & & .716 & & & & & \\
\hline & COE3 & & .706 & & & & & \\
\hline & COE2 & & .619 & & & & & \\
\hline \multirow{4}{*}{ Mutual Support } & MS4 & & & .776 & & & & \\
\hline & MS5 & & & .767 & & .364 & & \\
\hline & MS3 & & & .656 & & & & .364 \\
\hline & MS1 & & & .607 & & .377 & & .324 \\
\hline \multirow{3}{*}{ Value Diversity } & VD6 & & & & .831 & & & \\
\hline & VD5 & & & & .799 & & & \\
\hline & VD4 & & & & .712 & & & \\
\hline \multirow{3}{*}{ Trust } & Tru2 & & & & & .718 & & \\
\hline & Tru3 & & & & & .740 & & \\
\hline & Tru4 & & .414 & & & .580 & & \\
\hline \multirow{6}{*}{ Team Performance } & TP1 & & & & & & .794 & \\
\hline & ТР2 & & .386 & & & & .725 & \\
\hline & TP3 & & & & & & .606 & \\
\hline & TP7 & & & & & & .581 & \\
\hline & TP6 & & .438 & & & & .536 & \\
\hline & TP5 & & & & & & .518 & \\
\hline \multirow{4}{*}{ Communication } & Com5 & & & & & & & .776 \\
\hline & Com1 & & & & .422 & & & .763 \\
\hline & Com2 & & & & & & & .741 \\
\hline & Com4 & & & & & & & .638 \\
\hline
\end{tabular}

Note: Extraction Method: Principal Component Analysis. Rotation Method: Promax with Kaiser Normalization Cronbach's Alpha was used to examine internal consistency reliability of items. Table 2 illustrates reliability analysis results. Since the Cronbach's Alpha values of all the constructs except trust were greater than 0.7 [50], it was concluded that there is a good internal consistency in these constructs and they are reliable. Only trust construct has given a Cronbach's Alpha value of 0.683 . But it is fair enough to conclude that it is also reliable. since alpha value is very close to 0.7 . Therefore, it can be concluded that the constructs are reliable. According to the conceptual framework derived through literature review, there are six factors that were measured in this study. Thus, multiple regression analysis was performed to identify the factors that influence team performance in software development teams in Sri Lankan software development companies. As given in Table 3, all the factors except Mutual Support had a significant effect on Team Performance. Since the $p$-values of these factors were less than 0.05 except Mutual Support, this can be further confirmed. Therefore, it can be concluded with 95\% confidence, that Communication, Cohesion, Trust, Value Diversity and Coordination of Expertise have 
significant effect on Team performance.

Table 2: Reliability analysis

\begin{tabular}{ll}
\hline Construct & Cronbach's Alpha \\
\hline Communication & .703 \\
Mutual Support & .737 \\
Cohesion & .753 \\
Trust & .683 \\
Value Diversity & .717 \\
Coordination of Expertise & .781 \\
Team Performance & .704 \\
\hline
\end{tabular}

Table 3: Regression analysis output

\begin{tabular}{|c|c|c|c|c|c|}
\hline \multirow{2}{*}{ Model } & \multicolumn{2}{|c|}{$\begin{array}{l}\text { Unstandardized } \\
\text { Coefficients }\end{array}$} & \multirow{2}{*}{$\begin{array}{l}\text { Standardized } \\
\text { Coefficients } \\
\text { Beta }\end{array}$} & \multirow{2}{*}{$\mathrm{t}$} & \multirow{2}{*}{ Sig. } \\
\hline & B & Std. Error & & & \\
\hline (Constant) & 1.678 & .383 & & 4.379 & .000 \\
\hline Communication & .304 & .062 & .311 & 4.947 & .000 \\
\hline Mutual Support & -.068 & .051 & -.083 & -1.332 & .184 \\
\hline Cohesion & .150 & .065 & .175 & 2.308 & .022 \\
\hline Trust & .135 & .059 & .148 & 2.301 & .023 \\
\hline Value Diversity & .106 & .052 & .181 & 2.037 & .043 \\
\hline Coordination of Expertise & .125 & .030 & .183 & 4.116 & .000 \\
\hline
\end{tabular}

Dependent Variable: Team Performance

Regression analysis was performed again by excluding Mutual Support and considering only the significant factors (i.e. Communication, Cohesion, Trust, Value Diversity and Coordination of Expertise), and the output is given in Table 4.

The adjusted $R^{2}$ is 0.49 (see Table 4) which explained that this model explains $49 \%$ of the total variance of Team Performance.

ANOVA analysis of the multiple regression model is shown in Table 5. Since $p$-value of the model is less than 0.05 , it can be concluded that this model is significant with $95 \%$ level of confidence.

Table 4: Model summary

\begin{tabular}{|c|c|c|c|c|c|}
\hline Model & $\mathrm{R}$ & R Square & $\begin{array}{l}\text { Adjusted } \\
\text { Square }\end{array}$ & $\mathrm{R}$ & $\begin{array}{l}\text { Std. Error of the } \\
\text { Estimate }\end{array}$ \\
\hline 1 & $.709^{\mathrm{a}}$ & .502 & .488 & & .22071 \\
\hline
\end{tabular}

Predictors: (Constant), Coordination of Expertise, Communication, Trust, Cohesion, Value Diversity Dependent Variable: Team Performance 
Table 5: ANOVA for Multiple regression model

\begin{tabular}{llllll}
\hline Model & Sum of Squares & df & Mean Square & F & Sig. \\
\hline Regression & 8.748 & 5 & 1.750 & 35.917 & .000 \\
Residual & 8.671 & 178 & .049 & & \\
Total & 17.419 & 183 & & & \\
\hline
\end{tabular}

Dependent Variable: Team Performance

Predictors: (Constant), Coordination of Expertise, Communication, Trust, Cohesion, Value

Diversity

Table 6: Coefficient analysis results

\begin{tabular}{|c|c|c|c|c|c|c|c|c|}
\hline \multirow{2}{*}{\multicolumn{2}{|c|}{ Model }} & \multicolumn{2}{|c|}{$\begin{array}{l}\text { Unstandardized } \\
\text { Coefficients }\end{array}$} & \multirow{2}{*}{$\begin{array}{l}\text { Standardized } \\
\text { Coefficients }\end{array}$} & \multirow[t]{2}{*}{$\mathrm{t}$} & \multirow[t]{2}{*}{ Sig. } & \multicolumn{2}{|c|}{$\begin{array}{l}\text { Collinearity } \\
\text { Statistics }\end{array}$} \\
\hline & & $\mathrm{B}$ & Std. Error & & & & Tolerance & VIF \\
\hline (Constant) & & 1.470 & .351 & & 4.191 & .000 & & \\
\hline Communication & & .292 & .061 & .298 & 4.788 & .000 & .720 & 1.389 \\
\hline Cohesion & & .135 & .064 & .157 & 2.099 & .037 & .498 & 2.008 \\
\hline Trust & & .111 & .056 & .122 & 1.986 & .048 & .744 & 1.344 \\
\hline Value Diversity & & .134 & .048 & .229 & 2.802 & .006 & .421 & 2.377 \\
\hline $\begin{array}{l}\text { Coordination } \\
\text { Expertise }\end{array}$ & & .115 & .030 & .261 & 3.900 & .000 & .625 & 1.599 \\
\hline
\end{tabular}

Dependent Variable: Team Performance

As shown in Table 6, there were no multicollinearity issues between independent variables since the VIF values are very close to 1 . Therefore, the multiple regression model for this analysis can be expressed as given in Equation 1: Team Performance $=0.351+0.298 * X 1+0.157 * X 2+0.122 * X 3+0.229 * X 4+0.261 * X 5$

Note: $X 1$ = Communication; $X 2$ = Cohesion; $X 3$ = Trust; X4 = Value Diversity; X5 = Coordination of Expertise

Table 7: Outcome of hypotheses testing

\begin{tabular}{llll}
\hline Hypotheses & $\begin{array}{l}\text { Path } \\
\text { coefficient }(\boldsymbol{\beta})\end{array}$ & $\begin{array}{l}\boldsymbol{p} \\
\text { value }\end{array}$ & $\begin{array}{l}\text { Supported/ Not } \\
\text { supported }\end{array}$ \\
\hline H1: Communication $\rightarrow$ Team performance & 0.382 & 0.000 & Supported \\
H2: Mutual support $\rightarrow$ Team performance & -0.083 & 0.184 & Not Supported \\
H3: Group Cohesion $\rightarrow$ Team performance & 0.289 & 0.000 & Supported \\
H4: Team member trust $\rightarrow$ Team performance & 0.285 & 0.000 & Supported \\
H5: Value diversity $\rightarrow$ Team performance & 0.277 & 0.001 & Supported \\
H6: Coordination of expertise $\rightarrow$ Team performance & 0.210 & 0.002 & Supported \\
\hline
\end{tabular}

Since all these factors measured in same scale, we can order these factors effect on Team Performance according to weight of the model coefficients. Therefore, it can be said that Communication has highest and Trust has the lowest impact on Team Performance. Further, considering the coefficients of Communication, Cohesion, Trust, Value Diversity and Coordination of Expertise, it is evident that these factors have positive effect on Team Performance. Path coefficients $(\beta)$ which indicate the effect between research constructs were 
used to test the hypotheses [51]. Path coefficients $(\beta)$ and relevant $p$ values are given in Table 7 . Confidence level considered for testing the statistical significance was at $95 \%(\mathrm{p}<0.05)$.

\section{Discussion}

This section discusses the findings of the current study with the available literature. The purpose of this study was to examine the factors influencing the project team performance in software development projects. According to the study findings, except mutual support all other hypotheses were supported. This study argued that the frequent communications among team members are important to increase the performance of teams. According to the study findings, it was evident that the frequent effective communication among team members positively influenced team performance $(ß=0.382, p=0.000)$. This finding was consistent with prior research. Effective communication is critical to the success of a software development project [22,52,53]. In projects, both formal communications (i.e. scheduled meetings, written status reports) and informal communications (i.e. quick phone calls, short emails) are important whenever it is required [22]. According to [52], lack of communication creates recurring problems related to development effort, and to improve the communication among members of a software development team, an effective process and the infrastructure to support it must be provided. Hence, considering the above facts, it was evident that the frequent communications among team members are important to increase the project team performance. It was also found that group cohesion has a significant positive effect on team performance $(ß=0.289, p=0.000)$. Consistent with the previous study findings, scholars have proved team cohesion as an important factor for increasing team performance [7,39]. According to them, when a team is highly cohesive, a member's commitment and willingness to strive for excellence thrives. Team cohesion affects the extent to which members like one another, get along with each other, and trust and respect one another's abilities and opinions. Even though, these characteristics are difficult to observe, project managers and team leads should determine whether team members equally participate in group discussions and activities rather than forming cliques or subgroups of cohesive units. Also [33] identified that a cohesive team will demonstrate a spirit of togetherness and support for one another that help team members quickly resolve conflicts devoid of hard feelings. Further, according to the study findings trust had a significant positive effect on team performance $(ß=0.285, p=0.000)$. The finding was consistent with the finding of [47], where it was found that project manager always should facilitate open communications within team, as it is one of the best ways of developing trust which in turn affect team performance. Further, it was found, if a team doesn't have trust among members, it is just a group of individuals, working together, often making disappointing progress. As a team leader or project manager, always should facilitate open communications within team, as it is one of the best ways of developing trust. Further, knowing each other team members personally, prevent blaming for mistakes in front of others that will lowers morale, undermines trust, and is ultimately unproductive are some of other ways that will help increasing team trust. In this study value diversity had a positive influence on team performance $(\Omega=0.277, \mathrm{p}=0.001)$. Consistent with the study finding of [8] it identified values as the background guide for behavioural choices. Value diversity occurs when team members perceive different values and different perspectives with respect to the team's tasks, project goals or mission $[7,8]$. Accordingly, when team members share similar values they are more likely to agree on team goals, tasks and procedures that will help in reducing task conflicts [8]. Therefore, it can be concluded that value diversity among team members positively influence and increase software development team performance. According to 
the study findings coordination of expertise had a significant positive effect on increasing team performance in software development teams ( $\beta=0.210, p=0.002$ ). The findings of the prior studies were consistent with the current study. According to the findings of [22,25], it is important that every team member can contribute all task-relevant knowledge and experience to the team. Further [37] emphasized that expertise or specialized skills and knowledge as the most critical resource for software development teams, as software development industry is rapidly becoming innovative, and different project may require new knowledge or variation of existing knowledge or expertise to cater different client requirements. Thus, expertise must be managed and coordinated to leverage its potential [37]. To summarize the discussion on the findings, it was evident that Communication, Cohesion, Trust, Value Diversity and Coordination of Expertise positively influence in increasing Team Performance in software development projects.

\section{Contribution to theory and practice}

The purpose of this research was to identify the factors affecting software development team performance in the Sri Lankan IT industry. The findings of this study narrowed the research gap to a certain extent as there was no any published research conducted to identify the factors that help increasing team performance in software development projects in Sri Lanka. Though there were existing research studies conducted in this area in other countries, findings might not be directly applicable to Sri Lankan context as there are cultural differences and differences in peoples' attitudes. Today, many organizations invest hugely on software development projects. However, since the success rate of these projects remains low, and hence, lot of research were carried out to investigate how to achieve success in software development projects. Since, software development requires team effort to complete the project successfully, improving team performance has been an important topic among project managers, team leads and professionals who work in software development industry. According to the results of this study, it was evident that five factors had a strong positive influence on increasing performance of team members. Thus, the findings of this study provided vital information for the software development industry in Sri Lanka on what factors that they should emphasize on to increase the performance among team members.

\section{Limitations of the study}

There were few limitations of this study when generalizing the results. First, the scope of this study was limited to ten large-scale software development companies in Sri Lanka including 184 IT professionals (40 teams). Hence, this study may not easily generalize to a larger population, and generalization of results only applies to the domain of software development. Further, the results of the data analysis provided that mutual support does not have a strong positive or negative effect on team performance. However, literature provided that mutual support has a positive effect on team performance. Hence, further research is required on this to check and verify the real effect of mutual support on team performance in the software development context. However, since this study considered the Sri Lankan IT professionals, there can be a cultural influence that affected on developing mutual support in teams. Further, team performance can be measured at individual level as well. Since this study is focusing on measuring team performance at team level, this study can be expanded to study the impact of individual level performance of the team members on project success. 


\section{Conclusion}

Identifying the factors that influence performance of team members is crucial in software development industry, because software development requires a team effort. Thus, the purpose of this study was to examine the factors that influence the effective and efficient team performance within software development projects in Sri Lanka. According to the study findings, six factors were identified as influential factors namely: Communication, Cohesion, Trust, Value Diversity and Coordination Expertise. Mutual Support did not indicate any strong or moderate positive or negative effect on team performance. Among the independent variables considered for this study, it can be concluded that communication had the highest effect on team performance. However, there were few associated limitations of this study when generalizing the findings. Since this study was limited to ten large-scale software development companies in Sri Lanka, findings of this study may not be generalizable to a larger population and generalization of results only applies to the domain of software development. Further, this study focused only on measuring team level performance and not individual performance. Nevertheless, results of the current study confirmed the importance of identified influencing factors in software development teams as significant predictors of team performance. As an implication, software development companies in Sri Lanka can emphasize more on the factors identified in this study to increase the performance of team members in software development projects.

\section{Recommendations}

Recommendations are provided based on the findings of the study, to the IT companies in Sri Lanka on how to enhance performance of software development teams. Companies can facilitate frequent communication relevant to the project; conduct daily stand-up meetings to discuss project status, use Instant Messengers (IMs) such as Google Hangouts, Pidgin, Skype etc., which allows team members to discuss and clear doubts related to project requirements at any time even with client or project manager or team lead. Further, the organizations should facilitate 'team building' activities (personality-based team building activities and skill-based team building activities) that will increase team cohesion. Another important aspect is to build trust among team members through facilitating open communication to explain their problems as well as ideas, knowing each other team members personally, prevent blaming for mistakes in front of others. In building tams, project manager or team lead should carefully choose members with somewhat similar values. Finally, the companies could leverage the knowledge diversity among team members, reduce the task conflict and relationship conflicts, and facilitates better coordination of different expertise among team members to improve team performance in software development projects.

\section{References}

[1]. A. T. Fonseka. "Factors affecting the completion of Information Technology projects in Sri Lanka.” Sri Lanka Journal of Management, vol.14, pp.12-33, 2011.

[2]. A. Marambe and C. Jayasundara. "The challenges of offshore agile software development in Sri Lanka and effects on the project outcome.” Journal of Management Information Systems, vol.9, pp.10-20, 
2014.

[3]. Sri Lanka association of software and services companies. "Finance and accounting outsourcing sector of Sri Lanka. Internet: http://www.slasscom.lk/sites/default/files/FAO\%20Report\%202013.pdf. 2013 [Oct. 12, 2015]

[4]. Sri Lanka Export Development Board. "ICT Services overview. Internet: http://www.srilankabusiness.com/export-services/ict/. 2014 [Sep. 28, 2015].

[5]. S D Nagasinghe. "Impact of agile project management Practices on enhancing the IT project success in Sri Lanka.” International Conference on Business Management, vol.8, 2011.

[6]. Standish Group International. "Extream CHAOS. Internet:

https://www.classes.cs.uchicago.edu/archive/2014/.../Standish.Group.Chaos.2009.pdf. 2009 [Sep. 28. 2016].

[7]. E. Weimer. “The influence of teamwork quality on software development team performance.” Tilburg University. 2013.

[8]. T. Liang, C. Liu, T. Lin and B. Lin. "Effect of team diversity on software project performance." Industrial Management \& Data Systems, vol.7, pp.636-653, 2007.

[9]. J.T. Karlsen, J. Andersen, L. S. Birkely and E. Odegard. “An empirical study of critical success factors in IT projects.” International Journal of Management and Enterprise Development, vol.3, pp.297-311, 2006.

[10]. M. N. Faisal, D. K. Banwet and R. Shankar. "Mapping supply chains on risk and customer sensitivity dimensions.” Industrial Management \& Data Systems, vol.106, pp.878-95, 2006.

[11]. D. Murthy and G. Sreenivas. "Development of eAgromet Prototype to Improve the Performance of Integrated Agromet Advisory Service.” Journal of Education and Development using ICT, pp.168-188, 2014.

[12]. M. P. Buvik and M. Rolfsen. "Prior ties and trust development in project teams - a case study from the construction industry.” International Journal of Project Management, vol. 33, pp. 1484-1494, 2015.

[13] R. G. Koelmans. “Project success and performance evaluation.” Information and Management Journal, vol.41, pp. 229-236, 2004.

[14]. Y. Lindsjorn, D. I. K. Sjoberg, T. Dingsoyr, G. R. Bergersen and T. Dyba. "Teamwork quality and project success in software development: A survey of agile development teams.” Journal of Systems and Software, vol. 122, pp. 274-286, 2016. 
[15]. V. S. Anantatmula and P. F. Rad. "Role of Organizational Project Management Maturity Factors on Project Success.” Engineering Management Journal, vol. 30, pp. 165-178, 2018.

[16]. L.R. Yang, C. F. Huang and K. S. Wu. "The association among project manager's leadership style, teamwork and project success.” International Journal of Project Management, vol. 29, pp. 258-267, 2011.

[17]. R. G. Cooper. 'Winning at new products: Accelerating the process from idea to launch.” Journal of Product Innovation Management, vol.39, pp.1005-1023, 1993.

[18]. H. G. Gemuenden. 'Success factors of project management: The critical few.” Journal of Project Management, vol.90, pp.4-15, 1990.

[9]. A. Griffin and J. R. Hauser. "Patterns of communication among marketing, engineering and manufacturing: A comparison between two new product development teams,” Management Science, vol.38, pp.360-373, 1992.

[20]. A. M. Gondal \& A. Khan. "Impact of team empowerment on team performance case of the telecommunications industry in Islamabad.” International Review of Business Research Papers, vol.4, pp.138-146, 2008.

[21]. J. L. Dyer. “Team research and team training: A state-of-the-art review.” Human Factor review, pp. 285-325, 1984.

[22]. M. Hoegl and H. G. Gemuenden. "Teamwork quality and the success of innovative projects: A theoretical concept and empirical evidence.” Organization Science, vol.12, pp.435-449, 2001.

[23]. J. R. Katzenbach and D. K. Smith. The wisdom of teams: Creating the high-performance organization. Boston: Harvard Business Review Press, 1993.

[24]. D. L. Gladstein. “Groups in context: A model of task group effectiveness.” Administrative Science Quarterly, vol.29, pp.499-517, 1984.

[25]. J. R. Hackman. The design of work teams', in Lorsch, J (eds), Handbook of organizational behaviour, New York: Prentice Hall, 1987.

[26]. J. C. Henderson. “Involvement as a predictor of performance in US planning and design”, Working Paper No. 175, Center for Information Systems Research, Massachusetts Institute of Technology, Cambridge, MA, 1988.

[27]. E. Salas. “On teams, teamwork, and team performance: Discoveries and Development.” Journal of Human Factor Ergonomics Society, vol.50, pp.540-547, 2008. 
[28]. W. A. Ruch. "Measuring knowledge worker productivity.” Presented at the Conference on productivity research, New York, USA, 1980.

[29]. T. K. Abdel-hamid. "Investigating the impacts of managerial turnover/succession on software project performance.” Journal of Management Information Systems, vol.9, pp.127-144, 1992.

[30]. C. Deephouse, T. Mukhopadhyay, D. R. Goldenson and M. I. Kellner. "Software processes and project performance.” Journal of Management Information Systems, vol.12, pp.187-205, 1995.

[31]. J. J. Jiang, G. Klein and R. A. Pick. "The impact of IS department organizational environments upon project team performances.” Information \& Management, vol.40, pp.213-220, 2003.

[32]. A. Rai and H. Al-Hindi. "The effects of development process modelling and task uncertainty on development quality performance.” Information \& Management, vol.37, pp.335-346, 2000.

[33]. J. H. Bradley and F. J. Hebert. "The effect of personality type on team performance.” Journal of Management, vol.16, pp.337-353, 1997.

[34]. K. J. Stewart and S. Gosain. "The impact of ideology on effectiveness in open source software development teams.” Information Systems Research, vol.17, pp.126-144, 2006.

[35]. K. S. Jayawandene and H. Rajapaksha, “Team Working Practices and Team Orientation of Employee: A Comparative Study between the State and Private Banks in Sri Lanka.” Sri Lankan Journal of Human Resource Management, vol.4, pp.49-61, 2012.

[36]. M. B. Pinto and J. K. Pinto. "Project team communication and cross-functional cooperation in new program development.” Journal of Product Innovation Management, vol.7, pp.200-212, 1990.

[37]. S. Faraj and L. Sproull. "Coordinating expertise in software development teams.” Management Science, vol.46, pp.1554-1568, 2000.

[38]. J. E. Driskell, P. H. Radtke and E. Salas. "Virtual teams: Effects of technological mediation on team performance.” Group Dynamics: Theory, Research, and Practice, vol.7, pp.297-323, 2003.

[39]. A. V. Carron, W. N. Widmeyer and L. R. Brawley. “The development of an instrument to assess cohesion in sport teams: The group environment questionnaire.” Journal of Sport Psychology, vol.7, pp.244-266, 1985.

[40]. J. Ivancevich and M. Matteson. “Organizational level stress management interventions: a review and recommendations.” Journal of Organizational Behavior Management, vol.8, pp.229-248, 1987.

[41]. R. Bridges, G. Sherwood and C. Durham. "Measuring the influence of a mutual support educational intervention within a nursing team.” International Journal of Nursing Sciences, vol.1, pp.15-22, 2014. 
[42]. D. Tjosvold and M. M. Tjosvold. "Cross-functional teamwork: the challenge of involving professionals.” in Beyerlein, M M, Johnson, D A \& Beyerlein, S T (eds), Advances in Interdisciplinary Studies of Work Teams, JAI Press, Greenwich, CT, 1995.

[43]. K. A. Jehn. "Enhancing effectiveness: an investigation of advantages and disadvantages of value-based intra-groupconflict.” International Journal of Conflict Management, vol.5, pp.223-238, 1994.

[44]. D. McAllister. “Affect and cognition-based trust as foundations for interpersonal cooperation in organizations.” Academy of Management Journal, vol.38, pp.24-59, 1995.

[45]. S. L. Jarvenpaa and D. E. Leidner. “Communication and trust in global virtual teams.” Journal of Computer-Mediated Communication, vol.3, pp. 791-815, 1998.

[46]. E. Salas, Cannon-Bowers and J. H. Johnston. "How can you turn a team of experts into an expert team? Emerging training strategies.” in Zsambok, C E \& Klein, G (eds), Naturalistic Decision Making, Psychology Press, New York, 1997.

[47]. F. Friedlander. "The primacy of trust as a facilitator of further group accomplishment.” Journal of Applied Behavioural Science, vol.6, pp.387-400.1970.

[48]. N. Levina “Collaborating on Multiparty Information Systems Development Projects: A Collective Reflection-in-Action View.” Information Systems Research, vol.16, pp.109-130, 2005.

[49]. M. Barrett and E. Oborn. "Boundary object use in cross-cultural software development teams.” Human Relations, vol.63, pp.1199-1221, 2007.

[50]. J. F. Hair. Multivariate Data Analysis: A Global Perspective. Upper Saddle River: Prentice Hall, 2009. [51] Y. Fang, C. Chiu and E.T.G. Wang. "Understanding customers' satisfaction and repurchase intentions: An integration of IS success model, trust, and justice." Internet Research, Vol. 21, pp.479503, 2011.

[52]. B. Curtis, H. Krasner and N. Iscoe. "A field study of the software design process for large systems.” Communications of the ACM, vol.31, pp.1268-1287, 1988.

[53]. H. P. Fung and H. L. Siow. "Relationship between team satisfaction and project performance as perceived by project managers in Malaysia-A mixed methods study.” Open Journal of Social Science Research, vol.1, pp.283-249, 2013. 